\title{
Technè
}

La science au service de l'histoire de l'art et de la préservation des biens culturels

$47 \mid 2019$

Bernard Palissy : nouveaux regards sur la céramique française aux $\mathrm{XVI}^{\mathrm{e}}$ et $\mathrm{XVII}{ }^{\mathrm{e}}$ siècles

\section{Le bassin dit « du Déluge »}

Jessica Denis-Dupuis

\section{OpenEdition}

1 Journals

\section{Édition électronique}

URL : http://journals.openedition.org/techne/1509

DOI : 10.4000/techne.1509

ISSN : 2534-5168

Éditeur

C2RMF

\section{Édition imprimée}

Date de publication : 1 juin 2019

Pagination : 61

ISBN : 978-2-11-152830-7

ISSN : $1254-7867$

\section{Référence électronique}

Jessica Denis-Dupuis, « Le bassin dit « du Déluge » », Technè [En ligne], 47 | 2019, mis en ligne le 01 juin 2020, consulté le 21 décembre 2020. URL : http://journals.openedition.org/techne/1509 ; DOI : https://doi.org/10.4000/techne.1509

\section{(c) (i) (9)}

La revue Technè. La science au service de l'histoire de l'art et de la préservation des biens culturels est mise à disposition selon les termes de la Licence Creative Commons Attribution - Pas d'Utilisation Commerciale - Pas de Modification 4.0 International. 


\section{Le bassin dit « du Déluge »}

$\mathrm{P}$

ARMI le matériel découvert lors des fouilles de l'atelier de Bernard Palissy, les archéologues ont mis au jour les fragments d'un plat en terre cuite avec glaçure de couleur ocre (fig. 1) ${ }^{1}$. Le décor en relief de ces rebuts de cuisson est similaire à celui d'un bassin existant, dont un dessin a été publié pour la première fois en 1862 (fig. 2) ${ }^{2}$. Ce bassin, qui appartenait alors à un collectionneur anglais, passa vers la fin du XIX $\mathrm{X}^{\mathrm{e}}$ siècle dans la collection d'Alphonse de Rothschild. Il fut exposé au Petit Palais lors de l'Exposition rétrospective de l'Art français en 1900, puis Édouard de Rothschild hérita de la collection de son père. En 1952, sa collection fut étudiée $e^{3}$ et la photographie publiée à cette occasion permet de confirmer le lien direct entre cette pièce unique et les fragments découverts dans l'atelier des Tuileries. Le bassin dit « du Déluge » compte ainsi parmi les ouvres issues de l'atelier du maître saintongeais.

Il tire son nom de petits personnages se débattant parmi les flots représentés au fond du bassin entre l'îlot central et le marli. Le décor de l'aile, représentant des

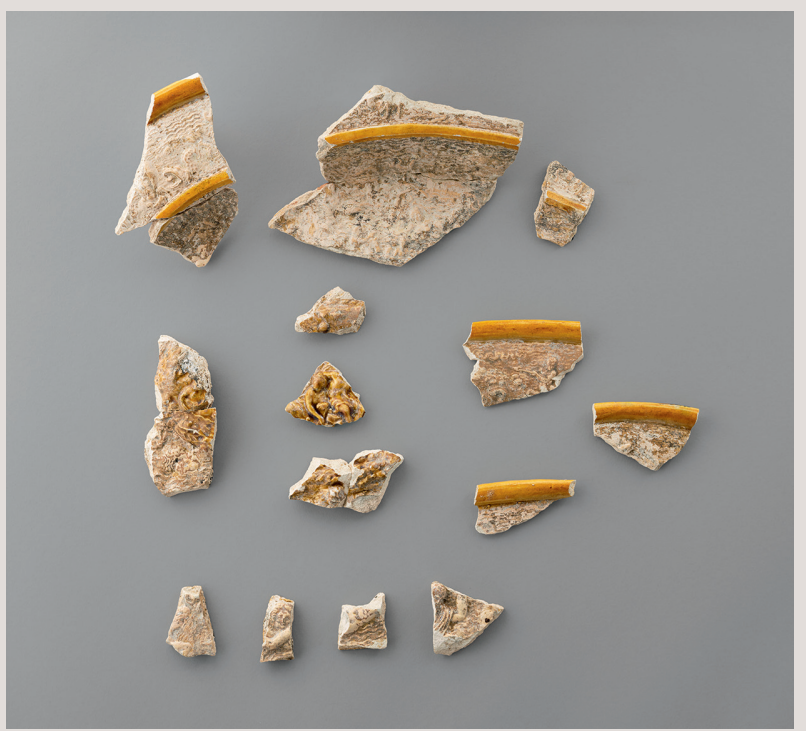

Fig. 1. Atelier de Bernard Palissy, Paris, fouilles des Tuileries, troisième quart du $\mathrm{xvI}^{\mathrm{e}}$ siècle, Fragments d'un plat à décor moulé : Le Déluge, terre cuite avec glaçure de couleur ocre,

Écouen, musée national de la Renaissance, EP 2835. (c) RMN-Grand Palais (musée national de la Renaissance, château d'Ecouen)/Mathieu Rabeau. scènes de combats marins, a été obtenu grâce à des moules en terre cuite, eux-mêmes issus du moulage direct de plaquettes d'orfèvrerie allemande. C'est également le cas du décor de l'îlot central qui provient d'une plaquette d'orfèvrerie représentant le Parnasse, datée vers 1560-1565 et attribuée à un atelier français ou flamand ${ }^{4}$. Le bassin est ainsi une création originale composée à partir de modèles d'orfèvrerie préexistants et sans lien entre eux. Le matériel archéologique découvert dans l'atelier des Tuileries (hors fragments liés au décor de la grotte) témoigne d'ailleurs presque exclusivement d'inspirations puisées dans les domaines de l'orfèvrerie ou des médailles, qui ont l'avantage d'être déjà en relief et dont l'empreinte peut être transposée sans difficulté par le céramiste dans un moule en plâtre ou en terre cuite.

Ce procédé technique n'a rien à voir avec les œuvres postérieures attribuées à Palissy ; il confirme l'originalité de la démarche du maître et le caractère d'art et d'essai de son atelier.

\section{Jessica Denis-Dupuis}

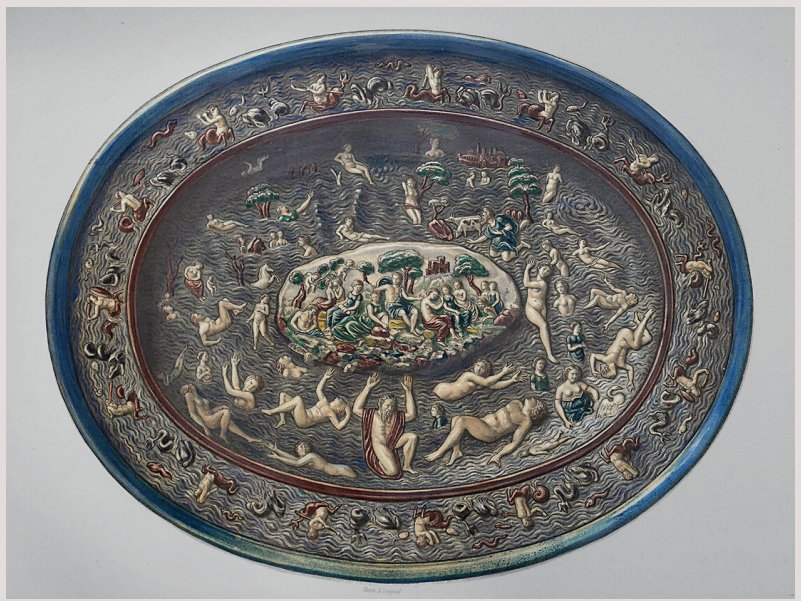

Fig. 2. Plat dit « du Déluge », chromolithographie dans Sauzay A., Delange H., 1862, Monographie de l'œuvre de Bernard Palissy, suivie d'un choix de ses continuateurs ou imitateurs, Paris, pl. 23. ㅇ DR.

Notes

1. Dufaÿ B. et al., 1987, « L'atelier parisien de Bernard Palissy ", Revue de l'Art, n 78, p. 33-60.

2. Sauzay A., Delange H., 1862, Monographie de l'œuvre de Bernard Palissy, suivie d'un choix de ses continuateurs ou imitateurs, Quai Voltaire, Paris, pl. 23.

3. Rothschild G. de, Grandjean S., 1952, Bernard Palissy et son école, Paris, pl. 16, catalogue $\mathrm{n}^{\circ} \mathrm{IV}$ (L. $\left.52 ; 1.40 \mathrm{~cm}\right)$.

4. Poulain D., 1992, «Bernard Palissy : Sources du répertoire décoratif de l'atelier des Tuileries », Albineana, 4, p. 187-200. 